\title{
REMOÇÃO CIRÚRGICA DE EXTRANUMERÁRIOS E TRACIONAMENTO ORTODÔNTICO DE INCISIVOS CENTRAIS SUPERIORES INCLUSOS
}

Wagner Leandro OLIVEIRA, Imara Castro MOROSINI, Camilla Fiedler FONÇATTI, Ricardo MORESCA, Luiz Antonio NERONE

Hiperdontia ou dentes extranumerários são alterações de desenvolvimento frequentes em muitas síndromes genéticas, porém raras em casos não sindrômicos. Este trabalho tem como objetivo discutir abordagens terapêuticas por meio do relato de um caso clínico de Hiperdontia, na ausência de patologia sistêmica associada, de um adolescente do gênero masculino, com 14 anos de idade, paciente do curso de Pós-graduação em Ortodontia da Universidade Federal do Paraná (UFPR). A presença de dentes extranumerários pode dificultar ou até mesmo impedir a erupção dos dentes adjacentes, prejudicando o desenvolvimento normal da oclusão dentária. Portanto, cabe ao Ortodontista e ao Cirurgião Buco-maxilo-facial o manejo desta anormalidade de forma a minimizar seus efeitos deletérios sobre a função mastigatória e a estética do sorriso.

Palavras -chave: Hiperdontia; Alterações de Desenvolvimento; Oclusão 